\title{
Application of an Instrumented Tracer in an Abrasion Mill for Rock Abrasion Studies
}

\author{
Tomaž Šolc ${ }^{1}$ - Aneta Stefanovska² - Trevor Hoey³ - Matjaž Mikoš4,* \\ 1 Jožef Stefan Institute, Slovenia \\ 2 Lancaster University, Department of Physics, United Kingdom \\ 3 University of Glasgow, Department of Geographical and Earth Sciences, United Kingdom \\ ${ }^{4}$ University of Ljubljana, Faculty of Civil and Geodetic Engineering, Slovenia
}

\begin{abstract}
One of research fields in studying dynamics of gravel-bed rivers is the interaction between sediment particles in motion and incision rates in rock-bottom river reaches. This natural phenomenon of rock abrasion was studied in a laboratory in a Dubree-type abrasion (tumbling) mill with the diameter of $711 \mathrm{~mm}$, using different mixtures of fluvial sediments as abrasive media. A set of rock plates of different lithologies was fixed to the inside mill wall to evaluate rock abrasion by moving sediment particles. The dynamics of the abrasion process of the rock plates was studied by a spherical instrumented tracer with the diameter of $99 \mathrm{~mm}$.

This paper describes our solution to the problem of recognizing and differentiating between impacts of the instrumented tracer with different bodies: sediment particles, rock plates, soft lining of the mill and steel side plates of the mill. For this purpose, the signal analysis of measured $3 D$ accelerations of the instrumented tracer gave sufficient information to recognize the tribological surrounding and sufficiently describe the intensity of the abrasion process (number and amplitudes of contact forces). An effective and computationally inexpensive algorithm for automatic impact recognition and evaluation was developed, based on time domain analysis. Furthermore, the frequency domain analysis gave a method for discriminating different signals. Both mentioned methods allow us to classify all recorded signals into groups based on similarity of measurement conditions.
\end{abstract}

Keywords: laboratory experiments, tribology, rock abrasion, instrumented tracers

\section{O INTRODUCTION}

Understanding sediment dynamics is of great importance in the field of gravel-bed river research. Advances in computer technology in the last few decades have stimulated the development of sophisticated sediment transport models. One major goal in this field is to develop accurate theoretical models based on physical laws of solid sediment particle interaction to amend or fully replace current semi-theoretical or experimental models based on various regression coefficients. This development is based largely on accurate understanding of sediment particle movement.

One of the research directions in gravel-bed river research is the interaction between sediment transport and river bed evolution that is of interest with regard to climate change [1], during large floods [2], and to estimate incision rates in bedrock river reaches [3]. There are different controls over bedrock riverbed incision, such as climate, tectonics and dynamics of surface processes [4] that include debris-flow scouring, land sliding, glaciation and fluvial incision. The latter is studied not only in the field but also under controlled laboratory conditions, such as studying rock abrasion in a laboratory and then transfering the measured laboratory relative values of rock abrasion into the field [5]. For such a transfer, it is important to have at least some idea of field values on erosion rates; we have shown how to collect field data when analyzing abrasion resistance of concrete on hydraulic structures - a hydropower plant [6].

As a part of this study at Glasgow University, we performed laboratory experiments on rock abrasion of fixed rock plates of different lithologies by moving sediment particles in an abrasion mill using instrumented tracer in order to help understand the process and intensity of measured rock abrasion. The main purpose of the tests presented in this paper was to check the effectiveness of the laboratory rock abrasion experiments rather than to develop a new rock abrasion model based on the number and intensity of particle impacts, i.e. integrating characteristics of the impacting sediment particles and the rock mechanical properties [7].

Using different instrumented tracers in the field of sediment transport research started some decades ago, proceeding a period of passive tracers such as painted sediment particles or magnetic tracers. The first line of further tracer development went into the usage of radio waves, and the second one into a more sophisticated development of instrumented tracers using pressure sensors or accelerometers to study sediment transport [8] and [9], but they were developed also to test rock-fall barriers [10], or to study debris-flow dynamics [11] and [12]. 


\section{INSTRUMENTED TRACER AND ABRASION MILL}

As a laboratory apparatus to study rock abrasion a Dubree type abrasion mill was selected with the inside diameter of $711 \mathrm{~mm}$, and the inside length (width) of $508 \mathrm{~mm}$, shown in Fig. 1. The mill consisted of a hollow steel cylinder, closed at both ends with steel and having rubber lining on its curved inner surface.

Test material was introduced to the cylinder through an opening in the top. The cylinder was mounted on a stub shaft, and rotated with 30 to 33 revolutions per minute around the horizontal axis. The abrasion mill was operated for 1 hour in each run. The travel distance of sediment particles in the mill was calculated by Wentworth's method, which is to multiply the mill inside circumference and the rotation velocity - this approach gave the travel distance of $4.02 \mathrm{~km} / \mathrm{h}$ [5]. The test material was weighted with the precision of $0.01 \mathrm{~g}$. The surface wear was studied using a 3-D laser scanner with the vertical precision of $0.047 \mathrm{~mm}$. The rock abrasion rates $\left[\mathrm{km}^{-1}\right]$ were determined as relative weight losses per $\mathrm{km}$ of the travel distance.

This set up closely resembles a Los-Angeles type of abrasion mill, used to assess the quality of crushed aggregates used in construction industry (e.g. in road construction) according to a standard ASTM C535 Standard Test Method for Resistance to Degradation of Large-Size Coarse Aggregate by Abrasion and Impact in the Los Angeles Machine.

The Los Angeles test is a measure of degradation of mineral aggregates of standard grading resulting from a combination of actions including abrasion or attrition, impact, and grinding in a rotating steel drum containing a specified number of steel spheres. The Los Angeles Abrasion test is widely used as an indicator of the relative quality or competence of coarse mineral aggregates larger than $19 \mathrm{~mm}(3 / 4 \mathrm{in}$.).

The main difference when studying rock abrasion was that no steel spheres were used as a charge but rather different mixtures of real fluvial sediment (different mass and number of sediment particles as well as of different lithologies, see Table 1) were introduced into the mill.

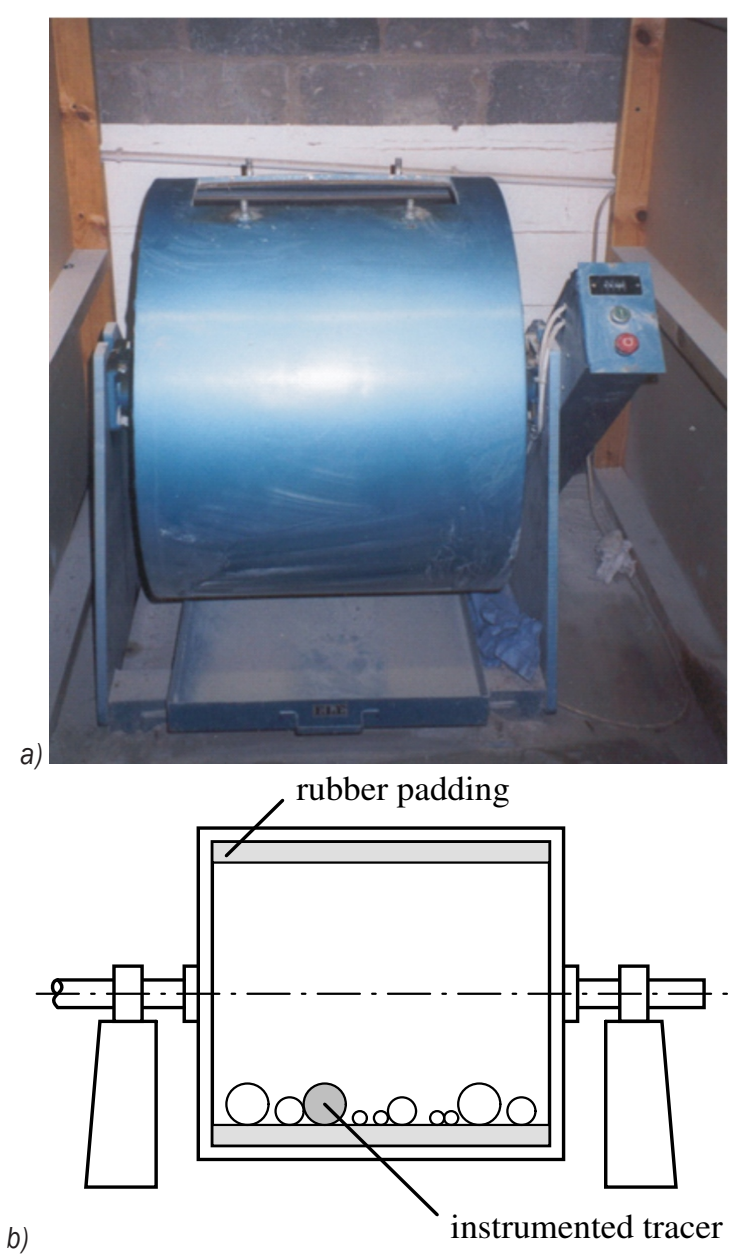

Fig. 1. a) The abrasion mill used in the rock abrasion experiments and $b)$ a vertical cross section through it

Both cases, the original Los Angeles mill tests and our rock abrasion experiments are dry and not wet abrasion tests and in this respect only to some extent resemble field conditions during sediment transport.

Table 1. Experimental conditions of various sediment sizes

\begin{tabular}{ccccc}
\hline Sediment mixture & $\begin{array}{c}\text { Initial mean weight and } \\
\text { standard deviation }[\mathrm{g}]\end{array}$ & $\begin{array}{c}\text { Number of } \\
\text { sediment particles }\end{array}$ & $\begin{array}{c}\text { Mean equivalent diameter } \\
{[\mathrm{cm}]}\end{array}$ & $\begin{array}{c}\text { Initial total weight } \\
{[\mathrm{g}]}\end{array}$ \\
\hline 1 & $48.15 / 4.83$ & 42 & 3.24 & 2022.49 \\
\hline 2 & $63.14 / 5.05$ & 33 & 3.55 & 2083.74 \\
\hline 3 & $83.44 / 8.68$ & 24 & 3.89 & 2002.45 \\
\hline 4 & $106.84 / 6.28$ & 19 & 4.23 & 2029.93 \\
\hline 5 & $192.72 / 49.17$ & 11 & 5.15 & 2119.94 \\
\hline 6 & $250.40 / 13.28$ & 8 & 5.62 & 2003.23 \\
\hline 7 & $334.81 / 25.28$ & 6 & 6.19 & 2008.85 \\
\hline 8 & $456.12 / 32.30$ & 5 & 6.86 & 2280.59 \\
\hline
\end{tabular}




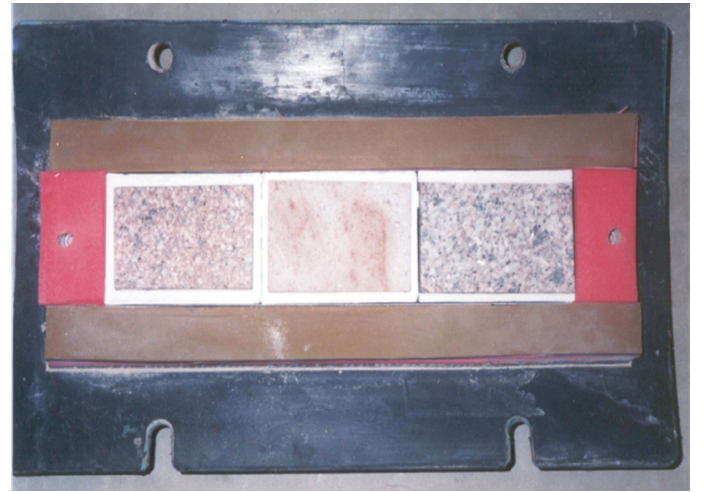

Fig. 2. Three rock plates installed on the inside part of the top of the mill (from [5])

A similar but wet and extensive laboratory study on abrasion of fluvial sediments from the Rhine River in Switzerland was conducted in an adapted cylindrical concrete mixer [13]. In order to be able to quantify measured abrasion coefficients, a study on motion of sediment mixtures in a revolving mixer was necessary [14].

The experiments described in this paper were dry rock abrasion experiments in a laboratory apparatus. Additionally, a set of 3 rock plates of different selected

lithologies from Scottish rivers was fixed to inside part of the mill top (see Fig. 2) to evaluate rock abrasion of these plates by moving sediment particles in the mill. Different combinations of sediment mixtures and rock plates were investigated (Table 2).

a)

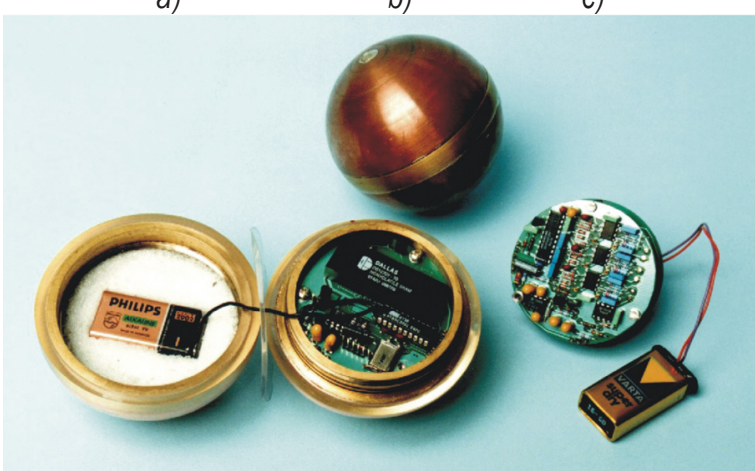

Fig. 3. SPY-Cobble and its constituent parts: a) opened tracer, b) the closed brass sphere with no epoxy coating, c) the two electronic boards and a battery

The dynamics of the abrasion process were described using an instrumented spherical tracer with the diameter of $99 \mathrm{~mm}$, and mass of $994.6 \mathrm{~g}$, shown in Fig. 3. The tracer was called SPY-Cobble (for Single

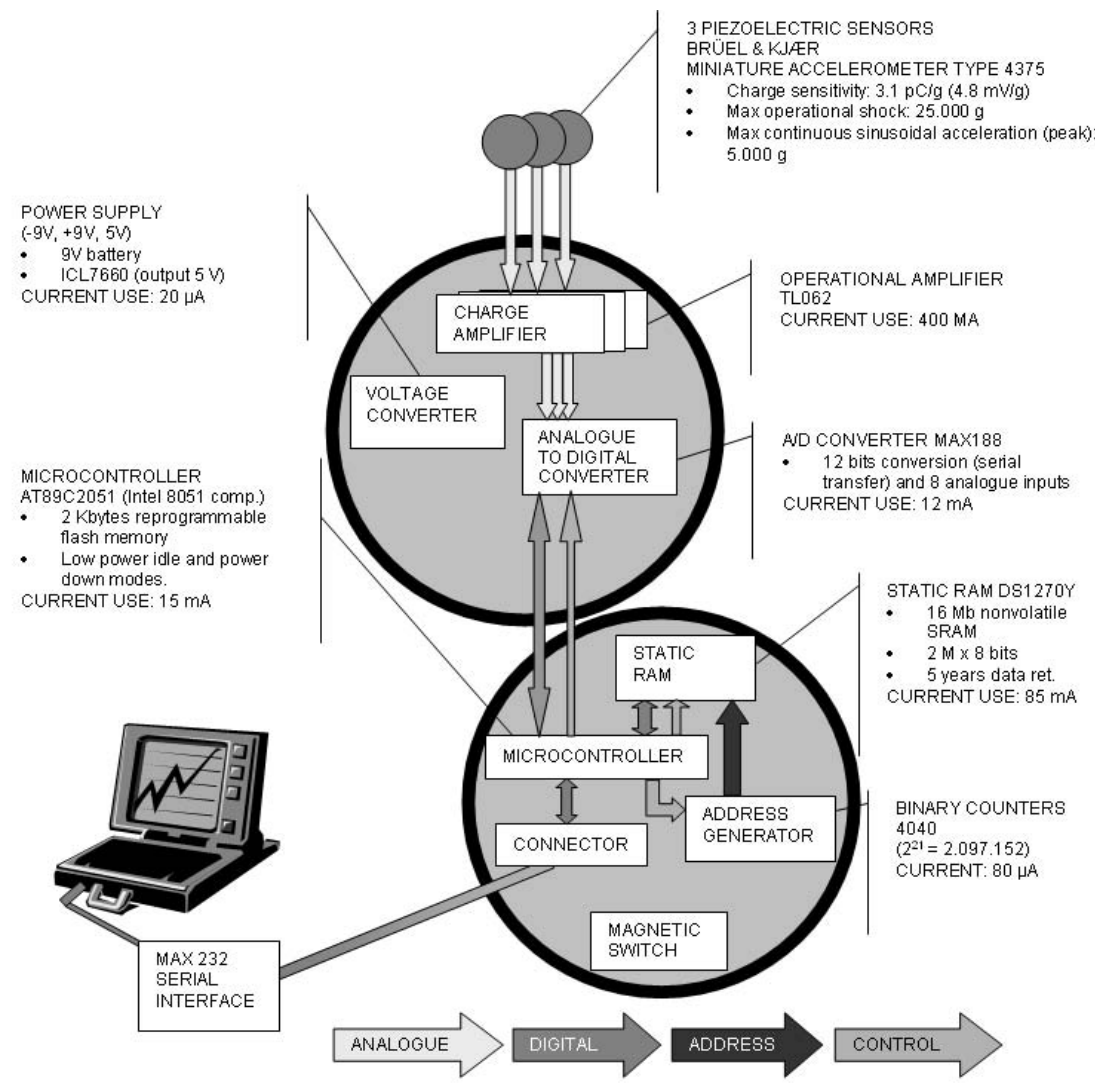

Fig. 4. Schematic view of the device 
Particle dYnamics) and its schematic view is shown in Fig. 4.

Table 2. Combinations of cylinder lining and sediment mixtures used in the mill

\begin{tabular}{cccc}
\hline $\mathrm{n}$ & Set label & Inner lining in cylinder & Sediment mixture \\
\hline 1 & $\mathrm{~g}$ & Rubber & None \\
\hline 2 & gr1 & Rubber & 1 \\
\hline 3 & gr4 & Rubber & 4 \\
\hline 4 & gr5 & Rubber & 5 \\
\hline 5 & gr8 & Rubber & 8 \\
\hline 6 & p & Rubber \& rock plates & None \\
\hline 7 & pg & Rubber \& rock plates & 1 \\
\hline 8 & pg5 & Rubber \& rock plates & 5 \\
\hline
\end{tabular}

It measures tracer accelerations in three perpendicular axes for at least 120 seconds only due to its internal memory restriction (2 MB Static Random Access Memory) [15]. The tracer realization is not sufficient for deducing its global position from the measurements. Nevertheless, knowing its mass it is straightforward to compute contact forces from measured acceleration data [16]. The tracer has been previously successfully tested under laboratory conditions in turbulent flows in laboratory flume at Free University in Berlin [17].

\section{RESULTS AND DISCUSSION ON SIGNAL PROCESSING OF MEASURED ACCELERATIONS}

The problem to solve was a tribological one: how can we recognize and differentiate between impacts of the instrumented tracer with different bodies: individual moving sediment particles, fixed rock plates, soft rubber lining of the mill and steel side plates of the mill? The starting point were the measured signals (one typical is shown in Fig. 5) during 8 sets of measurements under different conditions (Table 2), each set comprising of 10 runs. Each run was around 2 minutes long, and using the Wentworth's method, the tracer travelled for around $134 \mathrm{~m}$ during each run. This allows the number of impacts to be computed per $\mathrm{km}$ of the travel distance.

\subsection{Analysis of a Sinusoidal Signal}

We first focused on a typical sinusoidal signal as shown in Fig. 6 in a set without sediment particles or rock plates. The assumed reason for such a signal was rolling of the tracer along the cylinder surface. Typical time of a period $t_{0}$ was evaluated to be between 300 and $400 \mathrm{~ms}$. From it the rolling velocity in the mill can be estimated to be between $v_{i}=\pi d_{i} / t_{0}=80$ and

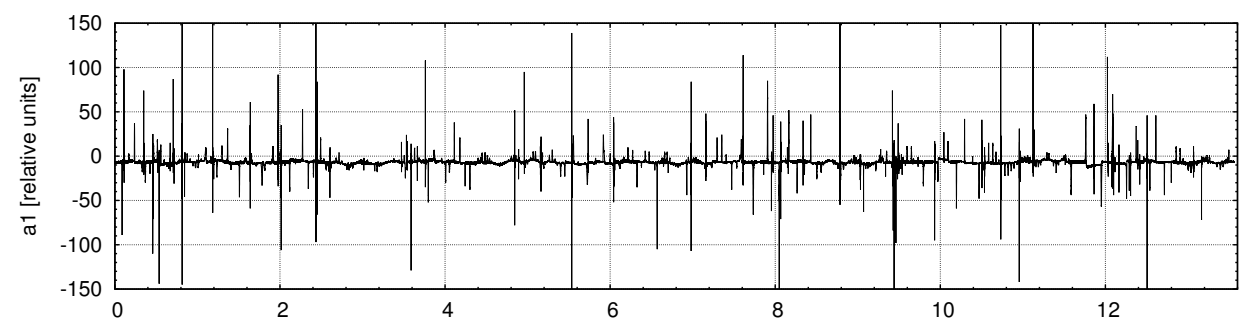

a)

$\mathrm{t}[\mathrm{s}]$

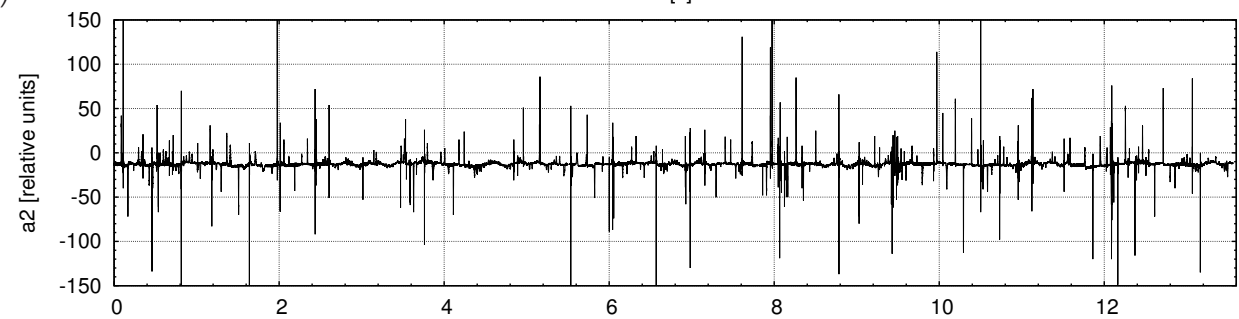

b) $\mathrm{t}[\mathrm{s}]$

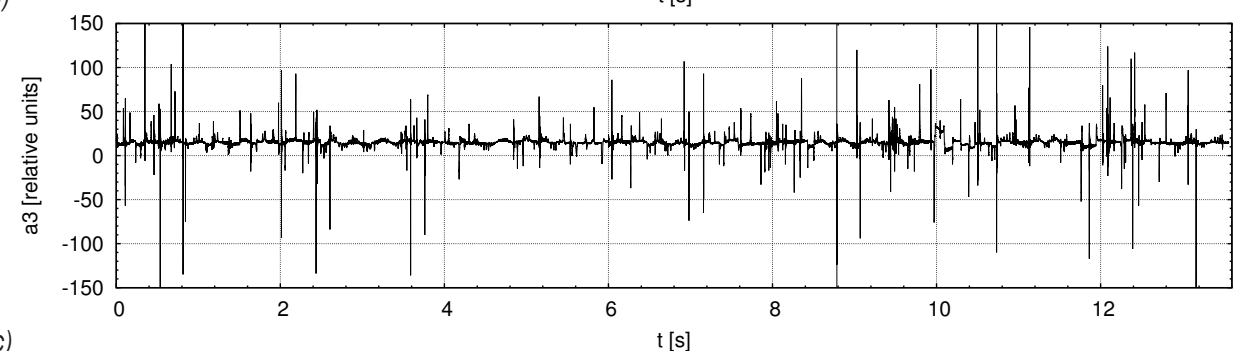

Fig. 5. Diagram of a typical signal from the set "gr1" - separated to three acceleration components, given in relative units of acceleration 
$100 \mathrm{~cm} / \mathrm{s}$, where $d_{i}=98 \mathrm{~mm}$ is the tracer diameter. This estimated tracer velocity corresponds well to the real circumferential mill velocity in the inner side of the mill wall, computed to be $v_{m}=\pi\left(\left(d_{m}-(2 \times 7)\right) \mathrm{mm}\right.$ $n=109$ to $120 \mathrm{~cm} / \mathrm{s}$, where $d_{m}=711 \mathrm{~mm}$ is the inner diameter of the mill. The thickness of the rubber lining is $7 \mathrm{~mm}$, and $n=30$ to $33 \mathrm{~min}^{-1}$ is the mill revolving velocity. The conclusion was made that the tracer rolled within the mill without much slipping due to rather high friction coefficient of the rubber lining.

When trying to describe the abrasion process between the sediment particles and the rock plates in the abrasion mill it is essential to know the number and amplitudes of single impacts between them. This abrasion process was not very effective in our case, since the particles were colliding with each other or with the rubber lining and only for a smaller part of time they hit 3 rock plates causing their abrasion. The full description of this rock abrasion analysis is given elsewhere [5].

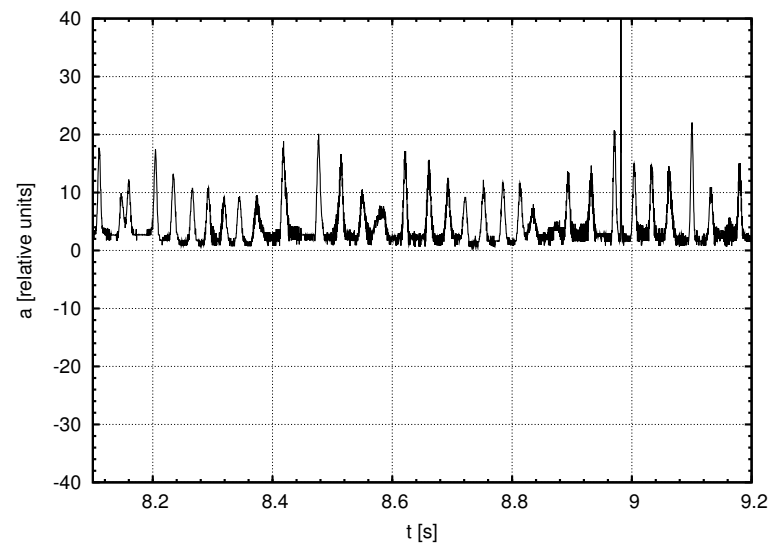

Fig. 6. A sinusoidal signal from the set "g": vector sum of all 3 measured acceleration components (in relative units of acceleration)

\subsection{Analysis in the Time Domain}

The tracer was used in this rock abrasion study only as an additional tool or as a substitute to describe the abrasion intensity. With this regard it was important to first develop a method for automatic impact recognition in measured signals which then enabled further evaluation of impacts in time domain. The developed method employed two parameters: A threshold $\mathrm{M}$ which the vector sum of accelerometer signals must exceed for an impact to be registered and a minimum time between two successive impacts $t_{\text {min }}$. The optimization of parameter values for the measured signals gave optimal values of $\mathrm{M}=20$ (relative units of acceleration) and $t_{\min }=3.53 \mathrm{~ms}$. These values were found the be the optimal compromise between filtering out uninteresting impacts due to friction and irregularities in the mill's inner surfaces and excluding interesting, but weak impacts to sediment particles/ rock plates.

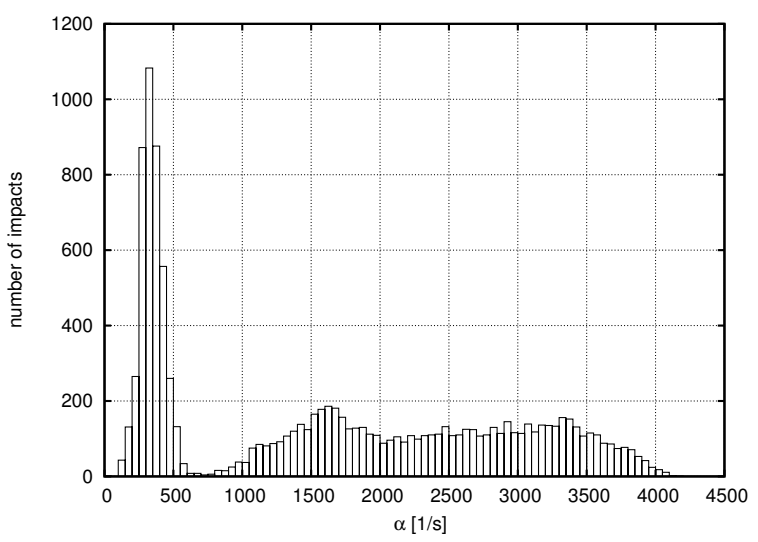

Fig. 7. Histogram of the $\alpha$ values for all recognized impacts

Table 3. Grouping of impacts using the $\alpha$ value

\begin{tabular}{cccc}
\hline \multirow{2}{*}{ Set label } & \multicolumn{3}{c}{ Number of impacts } \\
\cline { 2 - 4 } & $\alpha<700$ & $\alpha>700$ & sum \\
\hline $\mathrm{g}$ & 674 & 56 & 730 \\
\hline $\mathrm{gr} 1$ & 524 & 691 & 1215 \\
\hline $\mathrm{gr} 4$ & 466 & 2544 & 3010 \\
\hline $\mathrm{gr} 5$ & 526 & 992 & 1518 \\
\hline $\mathrm{gr} 8$ & 584 & 615 & 1199 \\
\hline $\mathrm{p}$ & 538 & 75 & 613 \\
\hline $\mathrm{pg}$ & 492 & 719 & 1211 \\
\hline $\mathrm{pg} 5$ & 465 & 1161 & 1626 \\
\hline
\end{tabular}

This approach enabled us to break continuous accelerometer signals into parts, each containing one tracer impact, suitable for further analysis. In order to distinguish between tracer impacts against different materials, we defined two values, which described each recognized impact: $\alpha=1 / T\left[\mathrm{~s}^{-1}\right]$ and $\beta=S /(1000 T)=\alpha(S / 1000)$ [s $\left.^{-1}\right]$, where $S$ is the local signal maximum (peak amplitude in relative units of acceleration) and $T$ is the time period $[\mathrm{s}]$ when the signal is higher than $(2 / 3 S)$. The impacts of short duration (small $T$ ) give large $\alpha$ values and vice-versa. The intense impacts (high $S$ ) give large $\beta$ values and vice-versa, the impact duration ( $T$ and $\alpha$ being the same)

If the $\alpha$ values for all automatically detected impacts in all available signals are computed and put into a histogram as shown in Fig. 7, it can be seen that impacts can be subdivided into two groups. The first one comprises impacts with values between $\alpha=$ 100 and $600 \mathrm{~s}^{-1}$, and the other one those with values 
between $\alpha=900$ and $4200 \mathrm{~s}^{-1}$. In the second group two peaks can be recognized: at $\alpha=1600$ and 3300 $\mathrm{s}^{-1}$. The total number of impacts is given for each set in Table 3.

From Table 3 it can be seen that the number of impacts with $\alpha<700 \mathrm{~s}^{-1}$ changes only to a minor extent when sediment particles were added to the mill. This was not true for the impacts with $\alpha>700 \mathrm{~s}^{-1}$ where the number of impacts was much influenced by the sediment mixtures used in the experiment (number of sediment particles in the mill). Therefore, it may be concluded that the impacts with $\alpha<700 \mathrm{~s}^{-1}$ are impacts against the rubber lining, and the second group, with $\alpha$ $>700 \mathrm{~s}^{-1}$, are impacts against sediment particles/rock plates and steel walls of the mill. As expected, the number of impacts against the rubber lining is slightly reduced when sediment particles are added as well as when the rock plates are installed in the mill (compare the sets "p", "pg" and "pg5"). The highest number of impacts was achieved with the set "gr4“.

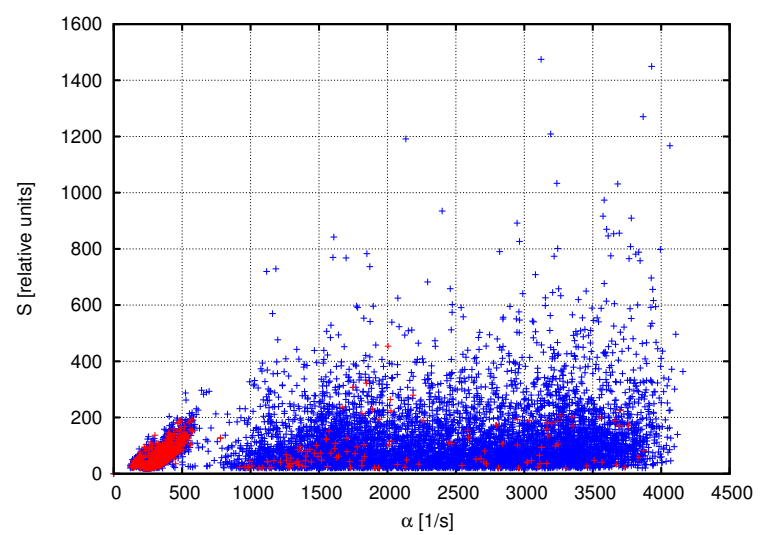

Fig. 8. The impact amplitude in relative units as a function of the $\alpha$ value. Sets without sediment particles (" $g$ " and " $p$ ") are given in red; the other sets are given in blue

The grouping of impacts can easily be seen on a diagram as in Fig. 8 showing the impact amplitudes as a function of the $\alpha$ value for all 80 runs. The value $\alpha=700 \mathrm{~s}^{-1}$ divides both groups, where the first one (impacts against the rubber lining) is limited with a line $S=2 / 5 \alpha$, where $S$ is the impact amplitude. For the impacts having $\alpha>700 \mathrm{~s}^{-1}$ there are no such sharp limits. Two peaks may be noticed: at $\alpha=1600$ and $3300 \mathrm{~s}^{-1}$. These two values correspond to the peaks in the histogram (see Fig. 7). The physical reason for these two peaks is not resembled yet and it is not caused by the difference between steel walls and sediment particles.

The large scatter of the impacts in the second group can be explained by the fact that we measured impacts of the tracer with sediment particles of different sizes, and that were of rather short duration. Such signals are very steep, and the sampling frequency would need to be increased from existing $2832 \mathrm{~Hz}$ in order to provide a representative record of such events.

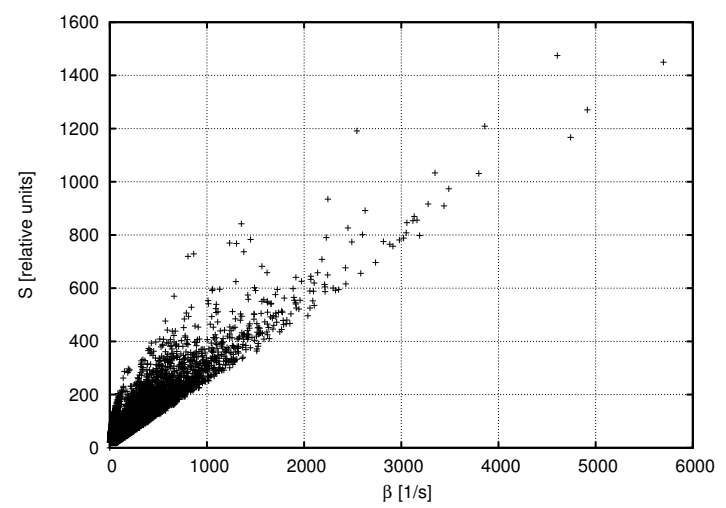

Fig. 9. The dependence of the impact amplitude $S$ in relative units on the $\beta$ value

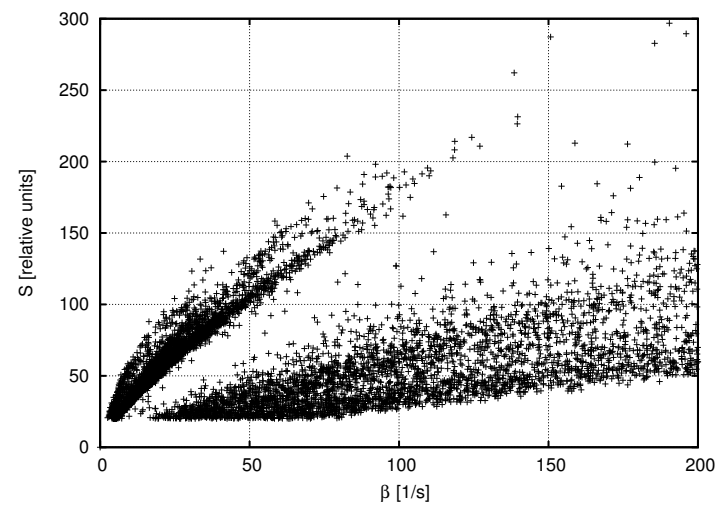

Fig. 10. The dependence of the impact amplitude $S$ in relative units on the $\beta$ value, given for low $\beta$ values (impacts when rolling or sliding) - lower-left corner of the Fig. 9

A grouping of the impacts is seen also in the diagram showing the dependence of the impact amplitudes $S$ on the $\beta$ value: $S=1000 T \beta$ (see Figs. 9 and 10). In Fig. 9, the lower part of the diagram is empty in accordance with the tracer sampling rate of $2832 \mathrm{~Hz}$. In Fig. 10, where this dependence is given for only low $\beta$ values, two groups can be distinguished, each exhibiting different duration of impact $(T)$. The division between the two groups is the $T=1 \mathrm{~ms}$; the upper-left group with $T>1 \mathrm{~ms}$ represents the impacts against the rubber lining, and the lower-right group with $T<1 \mathrm{~ms}$ represents all other impacts.

\subsection{Analysis in the Frequency Domain}

All the measured signals were also analysed in the frequency domain using a discreete Fourier 
transform of the vectorial sum of the accelerometer signals. Comparing histograms of absolute values of samples in frequency domain has given a method of discriminating different signals.

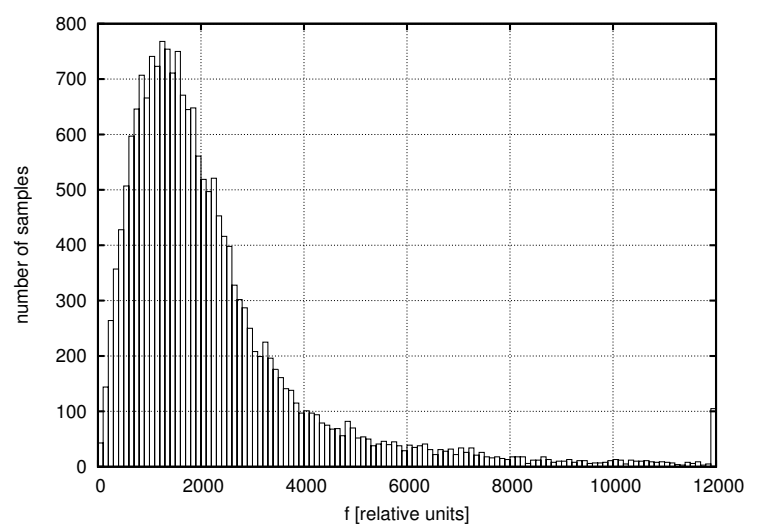

Fig. 11. Histogram of samples, given in relative units, of the discrete Fast Fourier transformation for one signal from the set "gr4"

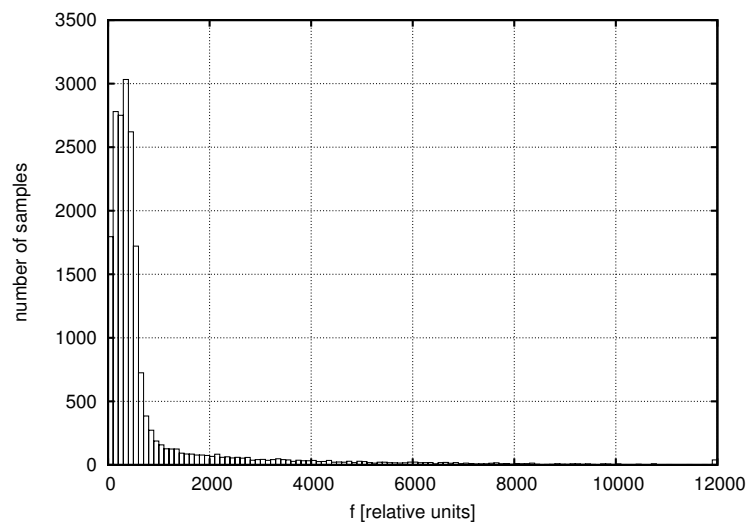

Fig. 12. Histogram of samples, given in relative units, of the discrete Fast Fourier transformation for one signal from the set "gr8"

Two typical histograms are given in Figs. 11 and 12, and their form for different sets can be compared between each other in Fig. 13; the rubber lining does not change the histogram form much (compare signals "gr11" and "pg1" with signals "gr51" and "pg51"). The comparison for signals within one set can be seen in Fig. 14.

The form of the histogram curve differs in width and peak position for different sets, but only using frequency analysis is not enough to distinguish between sediment mixtures. However using all relevant parameters of the abrasion process measured by the tracer (number of impacts, the $\alpha$ value, form and amplitude of the histogram of the discrete Fast Fourier Transform) allows reliable classification of an unknown signal to measured sets.

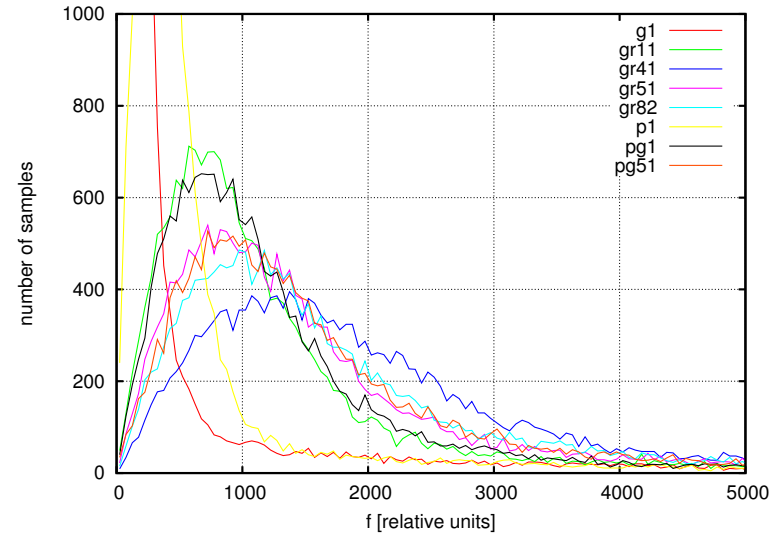

Fig. 13. A comparison between histograms of samples of the discrete Fast Fourier transformation for one signal from each set

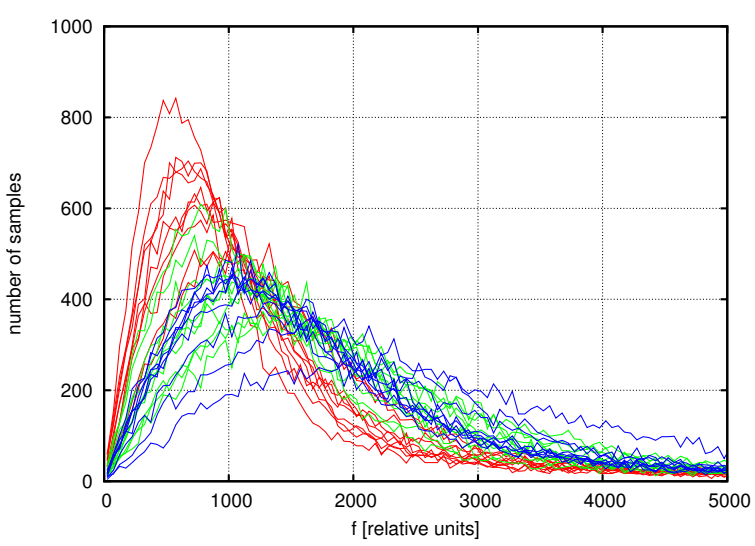

Fig. 14. A comparison between histograms of samples of the discrete Fast Fourier transformation for signals within one set ("gr1" in red, "gr5" in green, "gr8“ in blue)

\section{CONCLUSIONS}

We performed a laboratory study on rock abrasion in a laboratory abrasion mill that resembles the Los Angeles abrasion test. Instead of using steel balls as a charge like in the original Los Angeles abrasion tests, we used natural fluvial sediment mixtures of different gradation. Using an instrumented tracer with 3 installed piezoelectric accelerometers for around 2 minutes for each run, and by applying advanced signal processing of measured accelerations in the time domain, it was possible to automatically classify all recorded signals into groups based on the similarity of measurement conditions.

Such an approach makes it possible to describe the efficiency or intensity of the rock abrasion process in similar laboratory apparatus by number and amplitudes of impacts rather than by simply stating the equivalence between the travelled distance in the apparatus computed from the revolving mill velocity and the mill inner diameter, and the distance travelled 
in the field. Nevertheless, a full use of the results presented in this paper with the rock abrasion results presented in [5] still needs to be done. Until then, the major abrasion parameters remain sediment lithology and sediment size. But for any further analysis the results presented in this paper will be of value.

Anyhow, laboratory experiments on rock abrasion are still rather qualitative and are as such able to show differences between the different lithologies rather than quantitative and being able to measure real rock abrasion coefficients to be applied in the field.

Nevertheless, our laboratory attempt has shown that there are at least ways how to refine laboratory abrasion experiments by introducing instrumented tracers into the abrasion apparatus that can help to improve our knowledge about abrasion process in laboratory abrasion set-ups such as in an abrasion mill.

\section{ACKNOWLEDGEMENTS}

Both, the experiments and the analysis, were financed by The Royal Society of London as a part of the project "Automated Tracking of River Sediment Movement", under the collaboration of University of Glasgow (Dept. of Geographical and Earth Sciences), University Heriot-Watt in Edinburgh (School of the Built Environment) and University of Ljubljana (Faculty of Civil and Geodetic Engineering).

The signal analysis part of the study was prepared by the first author while studying at the Faculty of Electrical Engineering, University of Ljubljana.

\section{REFERENCES}

[1] Bogaart, P.W., van Balen, R.T. (2000). Numerical modeling of the response of alluvial rivers to Quaternary climate change. Global and Planetary Change, vol. 27, no. 1-4, p. 147-163, DOI:10.1016/ S0921-8181(01)00064-9.

[2] Wohl, E. (2007). Review of effects of large floods in resistant-boundary channels. Developments in Earth Surface Processes, vol. 11, p. 181-211, DOI:10.1016/ S0928-2025(07)11125-1.

[3] Sklar, L.S., Dietrich, W.E. (2006). The role of sediment in controlling steady-state bedrock channel slope: Implications of the saltation-abrasion incision model. Geomorphology, vol. 82, no. 1-2, p. 58-83, DOI:10.1016/j.geomorph.2005.08.019.

[4] Seong, Y.B., Owen, L.A., Bishop, M.P., Bush, A., Clendon, P., Copland, L., Finkel, R.C., Kamp, U., Shroder, Jr.J.F. (2008). Rates of fluvial bedrock incision within an actively uplifting orogen: Central Karakoram Mountains, northern Pakistan. Geomorphology, vol. 97, no. 3-4, p. 274-286, DOI:10.1016/j. geomorph.2007.08.011.

[5] Kim, J. (2004). Controls over bedrock channel incision. PhD Thesis, University of Glasgow, Glasgow.

[6] Kryžanowski, A., Mikoš, M., Šušteršič, J., Planinc, I. (2012). Abrasion Resistance of Concrete in Hydraulic Structures on Lower Sava River. Strojniški vestnik Journal of Mechanical Engineering, vol. 58, no. 4, p. 245-254, DOI: $10.5545 /$ sv-jme.2010.217.

[7] Acquaro, D. (2010). Impact of Solid Particulate on Brittle Materials. Strojniški vestnik - Journal of Mechanical Engineering, vol. 56, no. 4, p. 275-283.

[8] Ergenzinger, P., Schmidt, K.H., Busskamp, R. (1989). The pebble transmitter system (PETS): First results of a technique for studying coarse material erosion, transport and deposition. Zeitschrift für Geomorphologie Neue Folge, vol. 33, p. 503-508.

[9] Mikoš, M., Krzyk, M., Banovec, P. (1997). European project EROSLOPE and SPY-Cobble. Acta hydrotechnica, vol.15, no. 17, p. 125-136.

[10] Gerber, W., Grassl, H., Böll, A., Ammann, W. (2001). Flexible rockfall barriers - development, standardisation and type-setting in Switzerland. Proceedings of the International Conference on Landslides: Causes, Impacts, and Countermeasures, p. 515-524.

[11] Hanisch, J., Ergenzinger, P., Bonte, M. (2003). Dumpling - an "inteligent" boulder for studying internal processes of debris flows. Proceedings of the Third International Conference on Debris-flow Hazards Mitigation: Mechanics, Prediction, and Assessment, p. 843-849.

[12] Arattano, M., Marchi, L. (2008). Systems and sensors for debris-flow monitoring and warning. Sensors, vol. 8, p. 2436-2452, DOI:10.3390/s8042436.

[13] Mikoš, M. (1993). Fluvial abrasion of gravel sediments. Miteilungen der Versuchsanstalt für Wasserbau, Hydrologie und Glaziologie, no. 123, ETH, Zürich.

[14] Mikoš, M., Jaeggi, M.N.R. (1995). Experiments on motion of sediment mixtures in a tumbling mill to study fluvial abrasion. Journal of Hydraulic Research, vol. 33, no. 6, p. 751-772, DOI:10.1080/00221689509498550..

[15] Mikoš, M., Petrovčič, J., Spazzapan, M. (2001). A method and an apparatus for measuring of movement dynamics elements and forces acting upon single particles in natural environment. Patent no. P-9900222, The Slovenian Intellectual Property Office, Ljubljana.

[16] Spazzapan, M., Petrovčič, J., Mikoš, M. (2004). New tracer for monitoring dynamics of sediment transport in turbulent flows. Acta hydrotechnica, vol. 22, no. 37, p. 135-148.

[17] Mikoš, M., Spazzapan, M. (2005). Laboratory application of a satellite for monitoring dynamics of sediment transport in turbulent flows. Acta hydrotechnica, vol. 23 , no. 38 , p. 39-55. 